\title{
Demand Forecast on the Orchard Cold Chain Logistics in Hunan Province Based on Cognitive Neuroscience
}

\author{
Ying $\mathrm{Fu}^{1}$, Xiangpeng Zeng ${ }^{2}$, Yihua $\mathrm{Li}^{1 *}$, Yiming $\mathrm{Wen}^{3}$, Xiaowei Wen \\ ${ }^{1}$ College of Logistics and Transportation, Central South University of Forestry and Technology, \\ Changsha 410004, China \\ ${ }^{2}$ School of Medical Humanities and management, Hunan Medical College, Huaihua 418000, China \\ ${ }^{3}$ School of Mathematics, University of Birmingham, B15 2TT, United Kingdom \\ ${ }^{4}$ Department of Agricultural and Business Administration, South China Agricultural University, \\ Guangzhou 510642, China \\ *Email: yihua 1i21@163.com
}

Received: June 16, 2021. Revised: December 17, 2021. Accepted: January 13, 2022. Published: January 14, 2022.

\begin{abstract}
How to scientifically and effectively predict the cold chain logistics demand and provide basis for decision making has always been the focus of forestry and orchard logistics research. From the learning environment of neurons, cognitive neuroscience provides a new perspective for forecasting the demand for cold chain logistics. This paper uses the cognitive neuroscience theory to construct a BP neural network model containing two hidden layers to predict the cold chain logistics demand of the forestry and orchard industry in Hunan province in 2017-2021. Suggestions are then given from the aspects of cold chain logistics construction, transportation infrastructure construction, government policy, enterprise and industry according to the prediction results, thus, providing a theoretical basis for the planning of the cold chain logistics system of Hunan province in a certain period of time, as well as references for the development of cold chain logistics in other parts of the country.
\end{abstract}

Keywords-Fruit industry; Cold chain logistics; Demand forecasting; Cognitive neuroscience; Gray neural network.

\section{INTRODUCTION}

$\mathrm{H}$ unan province is located in the middle and lower reaches of the Yangtze River and is at $109^{\circ} \sim 114^{\circ} \mathrm{E}$ and $20^{\circ} \sim 30^{\circ} \mathrm{N}$. With typical continental subtropical monsoon humid climate, its average annual temperature is $16^{\circ} \mathrm{C} \sim 18^{\circ} \mathrm{C}$, and the average annual rainfall is $1200 \sim 1700 \mathrm{~mm}$ [1]. With rich land resources, the province is dominated by middle and low hills with many rivers and lakes, which are suitable for a variety of fruit trees. It is one of the provinces in China with the most abundant fruits and vegetables. There are fruit trees from 14 families, 24 genera and 48 species, dominating by Orange, pear, peach, grape, date, persimmon, pomelo trees and so on. In 2016, the production of garden fruit in Hunan accounted for $5 \%$ of the total fruit output of the whole country, of which citrus accounted for $13.2 \%$ of the total citrus, ranking the second in the whole country. At present, the fruit industry has become an important part of the gardening industry in Hunan Province, and plays an important role in promoting the increase of farmers' income as well as the efficiency of forestry. According to the data of forestry statistics yearbook of Hunan Province, since 2000, the planting area and production of fruit in the province has been increasing year by year. In 2016, the total output of the fruit was close to 20 billion yuan, ranking the first in terms of the output in all horticultural crops. Therefore, the fruit industry occupies an important position in the first industry of the province.

At present, domestic and foreign research on forest and fruit cold chain logistics can be roughly divided into the following three categories: In terms of cold chain logistics technology and its significance, Alomari et al. [2] proposed that modern information technology is a necessary means to improve the efficiency of cold chain transportation, and digital traceability Technology is an important guarantee for achieving food safety; Suchanek et al. [3] believes that optimizing production logistics can greatly reduce the total cost of enterprises and speed up capital turnover. In terms of cold chain logistics scheduling and optimization, Hsiao et al. [4] found that most of the path optimization problems in cold chain logistics use single vehicle delivery, while $\mathrm{Li}$ et al. [5] proposed that in the path 
optimization problem of cold chain logistics, multiple vehicles are compared with single vehicle delivery. It is more advantageous. In terms of cold-chain logistics demand forecasting, Intarapak et al. [6] used logistic regression forecasting to predict and analyze household debt in Bangkok and Thailand's metropolitan areas; Huang and Wang [7] used a combination model to forecast the cold-chain logistics demand for fresh agricultural products in my country. Avoid the shortcomings of a single prediction model; Li and Wang [8] found through comparison that the gray neural network model has higher prediction accuracy than the single gray prediction, linear regression and neural network methods.

In a word, the research of the above-mentioned domestic and foreign literature mainly focuses on agricultural products, meat and aquatic products, while there are relatively few discussions specifically on the cold chain logistics of forest and fruit. Therefore, this article will use a combination of gray and neural network methods to predict the demand for forest and fruit cold chain logistics in Hunan Province. It is hoped that through the research of this article, we will understand the general development trend of forest and fruit cold chain logistics in Hunan Province and strengthen relevant infrastructure for the government and enterprises. The construction provides data basis and improves the cold chain logistics management level.

\section{STATUS OF COLD CHAIN LOGISTICS OF FRUIT INDUSTRY IN HUNAN PROVINCE}

\section{Status of infrastructure devices}

$60 \%$ of the total cold storage in Hunan is concentrated in Chang-zhu-tan, Zhangsha. According to the statistics of the provincial development and reform commission, the total cold storage capacity of Chang-zhu-tan has reached 219300 tons till 2015, and 51 enterprises engaged in cold chain related businesses. Therefore, according to researches on the main cold storage of Hongxing, Wulipai, Shangdalong, Heishipu, Yangjiashan in Changsha and some supermrkets, the status of the cold storage in Hunan are listed as follows: Wulipai, upper big ridge, black stone shop and Yang Jiashan, and some supermarkets. 1) In terms of the classification of cold storage, the current urban operational cold storage, such as commercial refrigerators, is the most, while cold storehouses for processing are few. Low temperature cold storehouses occupy more than $90 \%$, while the high temperature ones are few. 2) As for the types of goods stored, most of the cold stores in the province are used for meat, aquatic products and dairy products storage. Cold stores for fruit account for less than 10\%, most of which are in supermarkets, and most of them are for high-grade fruits. Less than $20 \%$ locally produced fruits are refrigerated. 3) As for the construction of the cold stores, large cold stores in the province are dominated by traditional multi-layer large warehouse, which accounts for more than $90 \%$ of the total amount of cold stores in the province. This kind of cold store is in saves land and is often equipped with a trading market, for example, Hongxing. 4) In terms of the heat preservation facilities of the cold storage, the cold stores used in Hunan province now is mainly the old cold storage in the $60 \mathrm{~s}$ and $70 \mathrm{~s}$ of last century. The means of heat preservation of these cold stores are relatively backward, the rice husk is still used for heat preservation, while new polyamine PU and the extruded board XPS are rarely used.

\section{The current situation of cold chain logistics enterprises}

At present, 452 enterprises engaged in cold chain logistics in the province, most of which are small and medium-sized enterprises with small business scale and different service standards. Regional and large service network has not been formed; therefore, it is difficult to provide comprehensive integrated cold chain logistics services. According to the competition for " top 100 China's cold chain logistics enterprises in 2015" hold by China Federation of Logistics and Procurement, only one company in Hunan Province - Hunan Huinong Agricultural Logistics Co., Ltd. has been named [9].

\section{Human resources in cold chain industry}

At present, professionals in the cold chain logistics in Hunan are scarce, and the existing employees in the industry are mostly from the related industries. Being lacking of professional knowledge, they are not familiar with the characteristics of cold chain logistics and the operation specifications. According to the analysis of the curriculum standards and syllabus of the logistics professional colleges and universities in our province, there is no cold chain logistics specialty and no special courses for cold chain logistics at present. Although some schools provide classes for cold chain design as well as some courses for refrigeration technology, there is still no perfect training system.

\section{ANALYSIS OF RELEVANCE INDEX OF THE DEMAND INDEX SYSTEM OF FRUIT COLD CHAIN LOGISTICS}

\section{A. The construction of the demand index system}

According to the related data and the analysis of the present situation of the fruit in Hunan Province, the factors affecting the cold chain logistics can be divided into two categories: economic index and non-economic index [10]. Considering that non-economic indicators can not be expressed with quantitative data, this paper will mainly analyze the economic indicators in the construction of the logistics demand index system based on the principles of operability, authenticity and objectivity [11].

The index system for forecasting the demand for cold chain logistics in Hunan province is as follows:

\section{B. The establishment of cold chain logistics index system for} garden fruits

In order to make the prediction results more authentic and accurate, combined with the actual situation of Hunan Province, the paper corrected some of the influencing factors in the index system. This paper studies the cold chain logistics demand of garden fruits produced within the province and the indexes of garden fruit production are revised. The formula is: the output of self-produced garden fruit=total fruit output $* 85 \% * 65 \%$ of fruit and fruit. Since the data of per-capita consumption of garden fruits is difficult to collect, the national 
per-capita consumption of fruit is used for replacement. Therefore, the demand for garden fruits=the national per-capita consumption of garden * the number of permanent residents in Hunan province. In view of the various influencing factors in the logistics index system, relative statistics on the above 12 indexes and the total logistics demand (billion yuan) for the cold chain are collected according the statistical yearbook of Hunan Province, the statistical bulletin of Hunan Province, the Chinese Statistical Yearbook, the Chinese Rural Statistical Yearbook and the Chinese logistics yearbook, The data collected was shown in the following tables (Table 1).

C. Analysis of association degree of logistics index system of garden fruit cold chain of fruit

It can be seen from Table 2 that there are 13 quantitative indicators, of which are 12 independent variables, and $\mathrm{y}$ is dependent variables. Considering the different influence of the factors on the logistics demand in the garden fruit cold chain in
Hunan Province, the relationship between the 12 independent variables and the dependent variable is different. Therefore, it is necessary to analyze the association degree of these quantitative indexes which affect the logistics demand of the cold chain of garden fruits, and then the association degree between the 12 independent variables and the dependent variable can be obtained.

At present, many methods are used to analyze the association degree. Considering the correlation and timing between the two systems, and the complexity and interlacing of the relationship between the logistics demand of the cold chain and the related economic indicators, this paper will use the gray relational degree model to quantitatively analyze the relationship between the index system and the cold chain logistics of garden fruits. The association degrees between the 12 independent variables and the dependent variable can be obtained [12], as shown in the Table 3 .

Table 1. Indexes for logistics demand forecast of garden fruit

\begin{tabular}{|c|c|c|c|c|}
\hline Primary Index & Secondary Index & No. & Third-level Index & Unit \\
\hline \multirow{12}{*}{ Logistics demand of cold chain of garden fruit in Hunan } & \multirow{3}{*}{ Supply } & $\mathrm{X} 1$ & Fruit yield & ten thousand tons \\
\hline & & $\mathrm{X} 2$ & Planting area & thousand hectares \\
\hline & & $\mathrm{X} 3$ & Total value of out-put & ten thousand yuan \\
\hline & \multirow{3}{*}{ Demand } & $\mathrm{X} 4$ & Consumption of fruit & ten thousand tons \\
\hline & & $\mathrm{X} 5$ & Retail price index of fruit & $\%$ \\
\hline & & X6 & Disposable income of residents & yuan \\
\hline & \multirow{4}{*}{ Transportation } & $\mathrm{X} 7$ & Road mileage & kilometer \\
\hline & & $\mathrm{X} 8$ & Railway operating mileage & kilometer \\
\hline & & \begin{tabular}{|l|l|l}
$X 9$ \\
\end{tabular} & Highway freight volume & ten thousand tons \\
\hline & & $\mathrm{X} 10$ & Proportion of logistics to GDP & $\%$ \\
\hline & \multirow{2}{*}{ Construction Level } & $\mathrm{X} 11$ & Flow rate of cold chain & $\%$ \\
\hline & & $\mathrm{X} 12$ & Investment in fixed assets & 100 million yuan \\
\hline
\end{tabular}

Table 2. Forecast data of garden fruit cold chain logistics demand over the years

\begin{tabular}{|c|c|c|c|c|c|c|c|c|c|c|c|c|c|}
\hline Year & $\mathrm{X} 1$ & $\mathrm{X} 2$ & $\mathrm{X} 3$ & $\mathrm{X} 4$ & $\mathrm{X} 5$ & $\mathrm{X} 6$ & $\mathrm{X} 7$ & $\mathrm{X} 8$ & $\mathrm{X} 9$ & $\mathrm{X} 10$ & $\mathrm{X} 11$ & $\mathrm{X} 12$ & $\mathrm{Y}$ \\
\hline 2006 & 203.6 & 450.6 & 212667 & 238.9 & 102.2 & 6203 & 171848 & 2806 & 72457 & 18.5 & 4 & 396.9 & 36.9 \\
\hline 2007 & 228.2 & 480.8 & 475962 & 242.2 & 117.9 & 7255 & 175415 & 2779 & 85432 & 18.4 & 4.5 & 551.61 & 42.5 \\
\hline 2008 & 229.0 & 430.8 & 591540 & 230 & 102.2 & 8349 & 184568 & 2795 & 92148 & 18.2 & 4.6 & 775.92 & 46.7 \\
\hline 2009 & 250.9 & 469.2 & 673791 & 240.2 & 107.1 & 9098 & 191405 & 2894.8 & 111351 & 18.1 & 4.9 & 1024.94 & 49.1 \\
\hline 2010 & 261.4 & 519.7 & 1067748 & 245.1 & 114.3 & 11825 & 227998 & 3695 & 127635 & 17.8 & 5 & 1273.96 & 55.4 \\
\hline 2011 & 281.3 & 537.1 & 1160152 & 244.1 & 115.9 & 13403 & 232190 & 3693 & 144241 & 17.8 & 5.6 & 1267.65 & 63.7 \\
\hline 2012 & 325.0 & 546 & 1587014 & 267.6 & 99.7 & 14609 & 234051 & 3825 & 166670 & 17.9 & 6.2 & 1313.21 & 86.4 \\
\hline 2013 & 280.7 & 583.9 & 1656663 & 272.2 & 106 & 16004.9 & 235396 & 4038 & 185073.2 & 18 & 6.5 & 1474.93 & 82.5 \\
\hline 2014 & 294.2 & 563.9 & 1756311 & 279.6 & 114 & 17621.7 & 236250 & 4532 & 172612.7 & 16.6 & 7 & 1681.03 & 96.1 \\
\hline 2015 & 309.1 & 533.1 & 1823316 & 288.3 & 97.4 & 19317.5 & 236886 & 4521 & 184830.9 & 16.3 & 7.2 & 2076.37 & 113 \\
\hline 2016 & 336.6 & 538.9 & 2011023 & 305.2 & 98.3 & 21115 & 238142 & 4716 & 192039.3 & 16 & 7.9 & 2242.7 & 138.4 \\
\hline
\end{tabular}

Table 3. Association degree

\begin{tabular}{|c|c|c|c|c|c|c|c|c|c|c|c|c|}
\hline Variables & $\mathrm{X} 1$ & $\mathrm{X} 2$ & $\mathrm{X} 3$ & $\mathrm{X} 4$ & $\mathrm{X} 5$ & $\mathrm{X} 6$ & $\mathrm{X} 7$ & $\mathrm{X} 8$ & $\mathrm{X} 9$ & $\mathrm{X} 10$ & $\mathrm{X} 11$ & $\mathrm{X} 12$ \\
\hline$\gamma_{i j}$ & 0.789 & 0.675 & 0.762 & 0.853 & 0.566 & 0.843 & 0.701 & 0.814 & 0.750 & 0.463 & 0.857 & 0.831 \\
\hline
\end{tabular}

From the above table, we can see that the total logistics demand of cold chain are highly associated with the flow rate of cold chain $\mathrm{x} 11$ and the consumption of fruit $\mathrm{x} 4$. The the association degrees are 0.857 and 0.853 , respectively. The residents' disposable income $\mathrm{x} 6$, fixed assets input $\mathrm{x} 12$, railway operating mileage $\mathrm{x} 8$, fruit output $\mathrm{x} 1$, total output value $\mathrm{x} 3$, highway freight volume $\mathrm{x} 9$, road mileage $\mathrm{x} 7$ and fruit planting area $\mathrm{x} 2$ are highli associated with the total demand for garden fruit cold chain logistics. The price index $\mathrm{x} 5$ is weakly associated with the proportion of the logistics to the total GDP $\mathrm{x} 4$ and the logistics demand of the cold chain of Hunan province compared with other indexes, even though the 
association degree has been regarded as moderate.

IV. PREDICTION MODEL CONSTRUCTION OF THE GARDEN FRUIT COLD CHAIN LOGISTICS DEMAND IN HUNAN PROVINCE BASED ON COGNITIVE NEUROSCIENCE

Cognitive neuroscience is a discipline that uses neuroscience to study cognitive processes [13-16], including social cognition, decision-making, evolution, and some neuroimmunological and cognitive related research directions [17]. Based on the learning environment of neurons, gray neural network is used to study the prediction of cold chain logistics demand in Hunan province.

\section{A. Validity test of gray prediction model}

Gray prediction model is mainly used to predict independent variables [18-23]. Taking into account the number of independent variables, this paper takes the output of garden fruits in Hunan Province as an example to verify the gray prediction model. The training sample is the per capita GDP of Hunan province in 2006-2013. The test sample of forecast is the fruit yield in Hunan province in 2014-2016. The comparison of the forecast results of 2014-2016 output by the MTALAB gray model [24], the actual data is shown in Table 4:

Table 4. Gray forecast model results

\begin{tabular}{|c|c|c|c|}
\hline Year & $\begin{array}{c}\text { Forecast value (ten } \\
\text { thousand tons) }\end{array}$ & $\begin{array}{c}\text { Actual value (ten } \\
\text { thousand tons) }\end{array}$ & $\begin{array}{c}\text { Relative } \\
\text { error \% }\end{array}$ \\
\hline 2014 & 306.8 & 294.2 & $4.30 \%$ \\
\hline 2015 & 319.2 & 309.1 & $3.28 \%$ \\
\hline 2016 & 332.1 & 336.6 & $-1.33 \%$ \\
\hline
\end{tabular}

The above table shows that the relative error between the predicted value and the actual value is within 5\%, and the error is within the acceptable range, so it is effective to predict the independent variable by using the gray prediction model. Therefore, this model can be used to predict the development of the impact factors of the logistics demand forecast of the cold chain in Hunan province for the next five years (Tables 5-8).

Table 5. Gray prediction results of independent variables

\begin{tabular}{|c|c|c|c|c|c|c|c|c|c|c|c|c|}
\hline Year & $\mathrm{X} 1$ & $\mathrm{X} 2$ & $\mathrm{X} 3$ & $\mathrm{X} 4$ & $\mathrm{X} 5$ & $\mathrm{X} 6$ & $\mathrm{X} 7$ & $\mathrm{X} 8$ & $\mathrm{X} 9$ & $\mathrm{X} 10$ & $\mathrm{X} 11$ & $\mathrm{X} 12$ \\
\hline 2017 & 345.6 & 584.9 & 2540300 & 303.8 & 100.3 & 24395 & 259420 & 5190.9 & 225310 & 16.2 & 8.4 & 2565.4 \\
\hline 2018 & 359.5 & 597.7 & 2900700 & 312.5 & 99.1 & 27262 & 267660 & 5522.7 & 244760 & 15.9 & 8.9 & 2907.5 \\
\hline 2019 & 374.1 & 610.8 & 3312200 & 321.5 & 97.9 & 30465 & 276170 & 5875.7 & 265900 & 15.7 & 9.6 & 3295.3 \\
\hline 2020 & 389.2 & 624.2 & 3782200 & 330.8 & 96.7 & 34046 & 284940 & 6251.3 & 288870 & 15.5 & 10.3 & 3734.8 \\
\hline 2021 & 404.9 & 637.8 & 4318800 & 340.4 & 95.6 & 38047 & 294000 & 6650.9 & 313820 & 15.3 & 10.9 & 4232.8 \\
\hline
\end{tabular}

\section{B. Validity test of gray neural network model}

The predictions on the logistics demand of the cold chain in 2006-2014 and its influencing factors were selected as the training samples; the predictions on the logistics demand of the cold chain in 2013-2014 was chosen as the verifying sample; the predictions on the logistics demand of the cold chain in 2015-2016 was the test sample. Based on the training samples, verifying samples and test samples, relevant statistics of 2006-2016 were taken to build a BP neural network model containing two hidden layers [25], and MSE (Mean Square Error) was used to measure the training error, MSE is mean square error. The training process and the fitting results are shown in Figures 1-3.

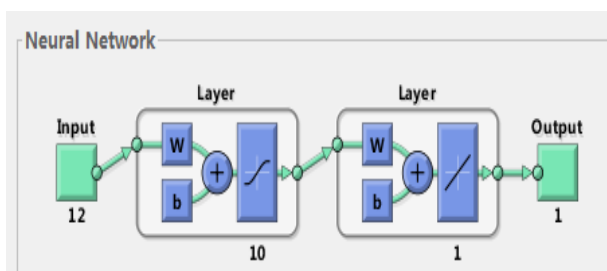

Figure 1. Schematic diagram of BP neural network element model

The transfer function of the first hidden layer is set to be Tansig function. The number of neurons is set to be 10 . The transfer function of the second hidden layer is set to be purelin function, and the number of neurons is set to be 1 . The number of iterations and the accuracy of the operation are reduced to the lowest, and the error of the fitting has been reduced to 0.01 through 147 iterations. Therefore, the gray neural network has been basically fitted [26], and the numbers of the training samples, verifying samples and the testing samples as well as the error statistics are:

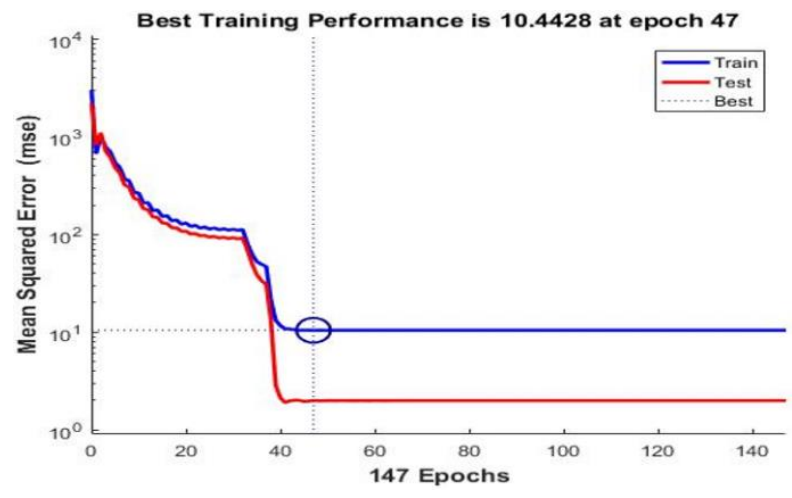

Figure 2. Gray neural network training diagram 


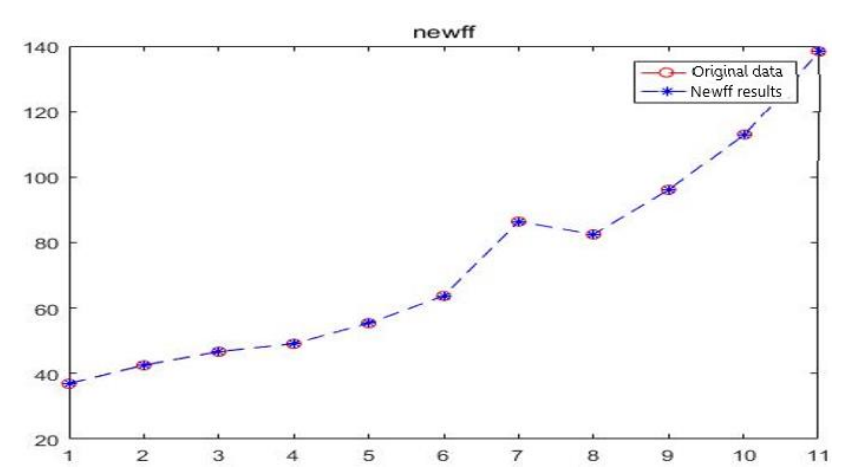

Figure 3. Gray neural network fitting diagram

Table 6. Error prediction of neural network prediction model

\begin{tabular}{|c|c|c|}
\hline & Number of samples & MSE \\
\hline Training & 7 & 3.443 \\
\hline Verifying & 2 & 0.235 \\
\hline Testing & 2 & 1.995 \\
\hline
\end{tabular}

On this basis, the verifying results of the 2013-2014, the testing results of 2015-2016 and the actual values are compared.

Table 7. Comparison between training results and actual values of neural network prediction models

\begin{tabular}{|c|c|c|c|}
\hline Year & Training results & Actual values & Errors \\
\hline 2013 & 82.1 & 82.5 & $-0.48 \%$ \\
\hline 2014 & 95.5 & 96.1 & $-0.62 \%$ \\
\hline 2015 & 114.2 & 113 & $1.06 \%$ \\
\hline 2016 & 140.7 & 138.4 & $1.67 \%$ \\
\hline
\end{tabular}

According to the above table, the error of the training and test samples are both within $2 \%$, the error is within the acceptable range, and the accuracy is higher than that of a single gray prediction model.

\section{Gray neural network prediction model}

According to the previous analysis, the effect of the gray neural network prediction model has been verified, therefore, the logistics demand of garden fruits cold chain in Hunan province of the next five years can be predicted by the gray neural network prediction model. The forecast results are as follows:

Table 8 . Forecast of total garden fruit cold chain logistics demand in Hunan province

\begin{tabular}{|c|c|}
\hline Year & $\begin{array}{c}\text { Total Garden Fruit Cold Chain Logistics Demand } \\
\text { in Hunan Province Y (100 million) }\end{array}$ \\
\hline 2017 & 151.1 \\
\hline 2018 & 173.2 \\
\hline 2019 & 198.7 \\
\hline 2020 & 227.9 \\
\hline 2021 & 261.4 \\
\hline
\end{tabular}

D. Suggestions on the development of the garden fruit cold chain logistics in Hunan province

According to the previous prediction results, the logistics demand of the garden fruit cold chain will show an upward trend in the next five years, which puts higher development requirements for the cold chain logistics. Based on the analysis of the factors affecting the logistics demand, suggestions are listed as follows:

(1) Increase investment in the facilities of garden fruit cold chain logistics

According to the previous analysis of the correlations between the 12 factors and the total logistics demand of the cold chain, the flow rate $\mathrm{x} 11$ is of the highest correlation with the total demand, and the correlation degree was 0.857 . Moreover, fixed assets investment $\mathrm{x} 12$ was highly associated with the total demand, which ranks the third. Therefore, the construction of cold chain logistics plays a vital role in the development of garden fruit cold chain logistics in Hunan province.

Based on the degree of relevance of the above indicators and combined with the problems existing in the cold chain logistics of forest and fruit in Hunan Province, the following suggestions are made:

First, increase the construction of refrigerated warehouses in production areas. Starting from the source, build cold storage in the fruit production areas, taking into account that the main fruit planting areas in Hunan Province are Taoyuan County, Shimen County, Yongxing County, Mayang Autonomous County, Qiyang County, and Yongshun County. Therefore, relying on the above six forest and fruit production areas to build a cold storage in the local area, and build a single-storey fresh-keeping cold storage warehouse. In addition, some processing places need to be planned in the cold storage warehouse for pre-cooling and preliminary processing of forest fruits.

Second, increase capital investment in distribution centers on cold chain logistics nodes. On the one hand, focus on improving the cold chain warehousing system, and build a batch of low-temperature distribution and processing centers for forest and fruit on the cold chain logistics nodes; on the other hand, accelerate the construction of the cold chain transportation system and vigorously develop third-party and fourth-party cold-chain logistics enterprises, Encourage and support third-party and fourth-party logistics enterprises to increase investment in the purchase of refrigerated transport vehicles, and encourage enterprises to upgrade and transform existing cold-chain vehicles.

Third, build a forest and fruit cold chain logistics information sharing platform. Using the "Internet +" thinking, with the help of advanced logistics technologies such as big data and cloud computing technology, GIS/GPS technology, and RFID technology, build a multi-channel, multi-level, and wide-coverage forest and fruit cold chain logistics information sharing platform. The forest fruit cold chain logistics information platform mainly includes three functional modules: forest fruit cold chain logistics information interaction platform, forest fruit cold chain logistics operation process platform and external interface management. Relying on the Linguo cold chain logistics information exchange platform, it realizes the sharing of information on the supply and demand of the forest and fruit between the "fruit purchaser and the forest and fruit retailer". Tracking the whole process from orchard to table; 
relying on the forest fruit cold chain logistics operation process platform, realize the sharing of vehicle information, warehousing information and location information of "forest fruit purchasers, logistics providers and forest fruit retailers" to promote resources Efficient use and reasonable configuration.

(2) Strengthen the construction of transportation infrastructure between the fruit producing areas and the consuming areas

By consulting relevant literatures and statistical yearbooks, the garden fruit producers are distributed in Huaihua, Yongzhou, Xiangxi Autonomous Prefecture, Chenzhou, Changde, Shaoyang and other hilly areas, accounting for nearly $58.44 \%$ of the total area of Hunan Province. However, the transportation infrastructure in these areas is relatively weak. The proportion of road total mileage and highway mileage to the total road mileage and highway mileage in the province are $49.4 \%$ and $50.4 \%$ respectively. The total highway mileage per unit area and the highway mileage are 0.95 and 0.023 respectively. Compared with 1.36 and 0.054 of Chang-zhu-tan area, there is a big gap. Therefore, first, increase the investment in the construction of transportation infrastructure between the producers and the markets, especially to increase the investment in the highway construction connecting them so that to ensure the smooth and rapid transportation of the fruit from the farmers to the markets. In this way, cases of unsalable fruits such as the Xiangxi's citrus can be reduced. Second, strengthen the construction of the expressways around the distribution center, rely on which, develop a garden fruit supply chain which integrates fruit packaging, transportation and sales, and thus form a batch of cold chain logistics bases covering a wide range with strong processing capacities.

(3) Policy improvement and cold chain standardization

Considering that the investment in infrastructure construction of cold chain logistics has the characteristics of long cycle and large scale, support from the government departments and industries including funds and policies are in needed. Specifically, first, preferential policies of garden fruit cold chain logistics should be promoted including reducing tax and fees, implementing land concessions, improving the financing environment of enterprises and other measures to reduce the operational pressure of enterprises. Second, promote the standardization of garden fruit cold chain logistics. Standards for storage temperature, transportation, packaging, packaging materials and quality testing should be carried out and the state ensured to be implemented with strict professional certification system and market access system.

(4) Promote co-ordinate development of production, learning and research through joint efforts of enterprises and the universities

Since the fresh fruits have short preservation time and are prone to be rot, the co-ordinate development of the production, learning and the research brooks no delay. According to the needs of users, relying on the university resources in the province to set up a special project group, insulation system, transportation route and storage strategy should be formulated to reduce the traditional circulation from production to consumption as much as possible, and thus to establish a sound, efficient and coherent logistics network. Only in this way can the fresh fruits and vegetables be quickly and safely transferred in to the final consumption link so that to benefit the end-users. Promote the development of the cold chain logistics industry association and erect a bridge of communication between enterprises and government through the combination of production, learning and research. Reduce vicious competitions in the industry and other bad phenomena by formulating corresponding standards for cold chain logistics market.

\section{CONCLUSION}

Through the research of this article, it provides data support for the construction of forest and fruit cold chain logistics in Hunan Province, so as to accelerate the high-quality development of cold chain logistics, and also provide reference for the development of cold chain logistics in other regions.

This article also has certain shortcomings, such as the extensiveness of data to be strengthened, and the selection of quantitative and qualitative index systems can be further improved. Therefore, in future research, we will focus on improving these two aspects to ensure higher prediction accuracy.

ACKNOWLEDGMENT

Hunan Provincial Social Science Fund Project (17YBA430); Research project of philosophy and social science in Hunan Province (16YBA380); The Key Project of NSFC (No. 71633002) named research of food risk identification and early warning in the production and supply process.

\section{References}

[1] R. Tan, Z. W. Wang, "Study on the present situation of cold chain logistics of Hunan agricultural products," Logistics Engineering and Management, Vol. 35, No. 12, pp. 5-7, 2013.

[2] S. A. Alomari, S. A. F. W. A. N. Al Salaimeh, E. M. R. A. N. Al Jarrah, M. S. Alzboon, "Enhanced Logistics Information Service Systems Performance: Using Theoretical Model and Cybernetics' Principles," Vol. 17, No. 29, pp. 278-287, 2020.

[3] P. Suchanek, F. Marecki, R. Bucki, E. Litavcova, "Logistic Optimization of the Production Centre," International Journal of Applied Mathematics, Computational Science and Systems Engineering, Vol. 3, pp. 6-11, 2021.

[4] Y. H. Hsiao, M. C. Chen, C. L. Chin, "Distribution planning for perishable foods in cold chains with quality concerns: Formulation and solution procedure," Trends in food science \& technology, Vol. 61, pp. 80-93, 2017.

[5] J. T. Li, M. Y. Liu, P. F. Liu, "Route optimization of multi-vehicle cold chain logistics for fresh agricultural products," Journal of China Agricultural University, Vol. 26, No. 7, pp. 115-123, 2021.

[6] S. U. K. A. N. Y. A. Intarapak, T. H. I. D. A. P. O. R. N. Supapakorn, "Application of Logistic Regression Analysis to Household Debt of Bangkok and Metropolitan Area of Thailand," WSEAS Transactions on Business and Economics, Vol. 17, pp. 676-681, 2020. 
[7] K. Huang, J. Wang, "Forecast and Analysis of Cold Chain Logistics Demand of Fresh Agricultural Products in China: Based on the Optimal Combination Model," Journal of Wuhan University of Technology (Information \& Management Engineering), Vol. 6, No. 42, pp. 524-530, 2020.

[8] X. L. Li, Z. J. Wang, "Coal logistics demand forecasting model based on improved grey neural network," Statistics and Decision, Vol. 18, pp. 82-85, 2015.

[9] H. J. Xie, "Study on the present situation of cold chain logistics of fresh agricultural products in Hunan Province and its development countermeasures," Logistics Technology, Vol. 37, No. 9, pp. 47-49, 2014.

[10] H. Li, T. Wu, J. Ran, J. J. Zhan, Y. T. Zhu, "Spatial coupling between specialized production of fruits and vegetables and front-end cold-chain logistics," International Journal of Design \& Nature and Ecodynamics, Vol. 15, No. 2, pp. 167-176, 2020.

[11] X. Wang, X. J. Wang, "Forecast analysis of the demand for cold chain logistics of agricultural products of Xinjiang urban residents," Logistics Technology, Vol. 33, No. 1, pp. 185-186, 2014.

[12] L. L. Ding, L. Y. Geng, "Least squares support vector machine logistics demand forecast based on grey correlation analysis," Logistics Technology, Vol. 32, No. 10, pp. 130-132, 2013.

[13] S. Q. Li, D. W. Zhuge, "The Application of Cognitive Neuroscience Methods in the Evaluation of Media Effects -- Taking TV drama ratings as an example," Modern Media, Vol. 242, No. 9, pp. 37-43, 2016.

[14] P. Y. Zhu, L. L. Sun, Y. F. Song, L. Wang, X. F. Yuan, Z. Dai, "Analysis on cognitive behaviors and prevention of human errors of coalmine hoist drivers," International Journal of Safety and Security Engineering, Vol. 10, No. 5, pp. 663-670, 2020.

[15] S. Gündoğdu, E. A. Doğan, E. Gülbetekin, Ö. H. Çolak, Ö. Polat, "Evaluation of the EEG signals and eye tracker data for working different N-back modes," Traitement du Signal, Vol. 36, No. 6, pp. 493-500, 2019.

[16] S. K. Veeramalla, V. K. H. R. Talari, "Estimation of neural sources from EEG measurements using sequential monte carlo method," Ingénierie des Systèmes d'Information, Vol. 24, No. 4, pp. 411-417, 2019.

[17]X. Y. Wang, "Brain control: human-machine fusion control based on brain-machine interface," Journal of Automation, Vol. 39, No. 3, pp. 208-221, 2013.

[18]F. Zhang, Y. X. Q. Zhang, H. Z. Dong, "Analysis of combined grey forecasting model on forecasting effect of logistics demand," Logistics Technology, Vol. 9, No. 33, pp. 221-223, 2014.

[19] K. R. Bhatele, S. S. Bhadauria, "Glioma segmentation and classification system based on proposed texture features extraction method and hybrid ensemble learning," Traitement du Signal, Vol. 37, No. 6, pp. 989-1001, 2020.

[20] B. H. Lohithashva, V. N. Manjunath Aradhya, D. S. Guru, "Violent video event detection based on integrated LBP and GLCM texture features,". Revue d'Intelligence Artificielle, Vol. 34, No. 2, pp. 179-187, 2020.

[21] S. L. Song, "Application of gray prediction and linear programming model in economic management," Mathematical Modelling of Engineering Problems, Vol. 5, No. 1, pp. 46-50, 2018.

[22]H. P. Wang, "An insurance sales prediction model based on deep learning,". Revue d'Intelligence Artificielle, Vol. 34, No. 3, pp. 315-321, 2020.

[23]P. K. Moganam, D. A. S. Seelan, "Perceptron neural network based machine learning approaches for leather defect detection and classification," Instrumentation Mesure Métrologie, Vol. 19, No. 6, pp. 421-429, 2020.

[24] Y. H. Zhao, Q. T. Niu, W. G. Zhou, "Matlab realization of prediction modeling of gray neural networks," Shanxi Architecture, Vol. 21, No. 7, pp. 255-257, 2017.

[25]P. Cao, F. Chen, "GA-Gray Neural Network Regional Logistics Demand Forecast," Journal of Beijing Institute of Technology (Social Science Edition), Vol. 14, No. 1, pp. 66-71, 2012.

[26] R. Li, Z. W. Li, "Forecast of Energy Demand in Logistics Industry Based on RBF Neural Network," Resource Science, Vol. 38, No. 3, pp. 450-460, 2016.

Ying Fu (1972-) Female, from Xiangtan, Hunan Province, doctor, associate professor of Central South University of Forestry and Technology, supervisor of master students, and famous teacher of ideological and political education of Ministry of Education. Research interests: Regional Logistics and supply chain management, logistics distribution, e-commerce logistics.

Xiangpeng Zeng (1993-) Female, from Shaoyang, Hunan Province, Master, teacher, School of medical humanities and management, Hunan Medical College, Research interest: Regional Logistics.

Yihua Li (1975-) Male, from Chaling County, Hunan Province, associate professor, doctor, supervisor of Master Students, Central South University of Forestry and Technology. Research Interests: Agricultural and Forestry Products Logistics, logistics and supply chain management.

Yiming Wen (1998-) Male, from Wuhu, Anhui, School of Mathematics, University of Birmingham. Research Interests: Supply Chain Finance.

Xiaowei Wen (1975-) Male, from Xiangtan, Hunan. Professor, South China Agricultural University, Associate Director, professor, South China Agricultural University. Selected Guangdong Province "one thousand, one hundred and ten project" province-level personnel training object.

\section{Creative Commons Attribution License 4.0 (Attribution 4.0 International, CC BY 4.0)}

This article is published under the terms of the Creative Commons Attribution License 4.0 https://creativecommons.org/licenses/by/4.0/deed.en_US 